\title{
Liver Function and Lipid Profile in adult Men in Eastern Zone of Kogi State, Nigeria
}

\author{
Zainab Yahaya ${ }^{1}$, Adam Abdullahi Adam², Asma'u Mahe², \\ Obidoa Onyechi ${ }^{3}$ and Sanni Momoh ${ }^{1}$
}

\author{
${ }^{1}$ Biochemistry Department, \\ Kogi State University, Ayingba \\ Kogi State Nigeria \\ 2Biochemistry Department, \\ Federal University Dutse, \\ PMB 7156, \\ Dutse Jigawa State Nigeria \\ ${ }^{3}$ Biochemistry Department, \\ University of Nigeria, Nsukka
}

Email: adam.a@fud.edu.ng

\begin{abstract}
Aspartate aminotransferase (AST) and alanine aminotransferase (ALT) are enzymes found mainly in the liver. When the liver is diseased or damaged, additional aspartate aminotransferase and alanine aminotransferase are released into the blood stream, causing the levels of the enzymes to rise. Therefore, the amount of aspartate aminotransferase and alanine aminotransferase in the blood is directly related to the extent of the tissue damage. Alkaline phosphatase (ALP) in mammals is found mainly in the liver. Increase in serum alkaline phosphatase level is associated with malignant biliary obstruction, primary biliary cirrhosis, primary sclerosing cholangitis, hepatic lymphoma and sarcoidosis. Cholesterol is component of plasma membranes. Triglycerides are found in adipose tissue, some triglycerides are stored in the blood to provide fuel for the muscles. This work was aimed at providing information on the values of liver function indices and lipid profile in apparently healthy ageing men residing within Kogi Eastern zone of Nigeria. This is as a result of the curiosity to know and make comparison between their parameters with those of the standard/reference or normal laboratory values. The subjects were divided into different groups 25 - 75 years and the mean and standard deviation of each parameter was calculated. Test for Liver function and lipid profile were carried out to determine the level of alkaline phosphatase, AST, ALT, TG, LDL, HDL and VLDL. There was a significant increase $(p<0.05)$ in the alkaline phosphatase of group 6 (75 years and above) when compared to the standard while the AST and ALT showed no significant difference. The lipid profile showed no significant difference as they were in tandem with the reference values.
\end{abstract}

Keywords: Low Density Lipoprotein, High Density Lipoprotein, Triacylglycerides, Very Low Density Lipoprotein, Aspartate Aminotransferase, Alanine Aminotransferase 


\section{INTRODUCTION}

Ageing affects different organs, tissues, and cell types in the same organism in different ways; that is, the extent of age-associated perturbations of structure and function is sitespecific. The effects of aging on the mammalian liver have not been clearly resolved. Aspartate aminotransferase (AST) and alanine aminotransferase (ALT) are enzymes found mainly in the liver, but also found in the red blood cells, heart cells, muscle tissue, pancreas and kidneys. When body tissues or an organ such as the liver or heart is diseased or damaged, additional aspartate aminotransferase and alanine aminotransferase are released into the blood stream, causing the levels of the enzymes to rise. Therefore, the amount of aspartate aminotransferase and alanine aminotransferase in the blood is directly related to the extent of the tissue damage (Sampson et al., 1980). Alkaline phosphatase (ALP) in mammals is found mainly in the liver and bones. Increase in serum alkaline phosphatase level known as hyperalkaline-phosphatasemia is associated with malignant biliary obstruction, primary biliary cirrhosis, primary sclerosing cholangitis, hepatic lymphoma and sarcoidosis.

The lipids (total cholesterol, triglycerides, low-density lipoprotein [LDL] cholesterol, and high-density lipoprotein [HDL] cholesterol) levels are similar in both genders in all age groups before adolescence (Bagatell \& Bremner, 1995). In boys, after puberty, the levels of total cholesterol, LDL cholesterol, and triglycerides increase slightly whereas the plasma level of HDL cholesterol decreases (Bagatell \& Bremner, 1995). This negative influence of androgens in men and the positive influence of estrogens in women are responsible, at least in part, for higher impact of atherogenesis in men compared with women (Bagatell \& Bremner, 1995; Zmuda et al., 1997). Aging in men enhances this negative influence of androgens on the lipid profile (Khaw \& Barrett-Connor, 1991; Zmuda et al., 1997;). The low levels of testosterone and high levels of free androgens index (defined as testosterone $(\mathrm{nmol} / \mathrm{L}) / \mathrm{SHBG}(\mathrm{nmol} / \mathrm{L}) \times 100)$ are associated with the atherogenic lipid profile in men (Andersen et al., 2000; Khaw \& BarrettConnor, 1991; Zmuda et al., 1997).

Cholesterol is component of plasma membranes; it is used to synthesize hormones and forms bile acids essential for digestion. Triglycerides are found in adipose tissue, some triglycerides are stored in the blood to provide fuel for the muscles (Sidhu and Naugler, 2012). High density lipoprotein (HDL) carries cholesterol in the blood and is considered beneficial because it removes excess cholesterol from the circulation and arterial walls and disposes of it; hence HDL is known as the "good cholesterol" The higher the level of HDL, the lower the risk of heart disease. Low density lipoprotein (LDL) carries cholesterol in the blood, but instead of disposing of excess cholesterol, LDL deposits excess in blood vessel walls. It is also known as the "bad cholesterol". Very low density lipoprotein (VLDL) carries triglycerides in the body. Increased VLDL level is associated with increased risk of artherosclerosis and coronary artery disease.

This work was aimed at providing information on the variations of Liver function parameters and lipid profile among age men of Kogi East senatorial district.

\section{MATERIAL AND METHODS}

\section{Experimental Design}

The study was carried out in Kogi east comprising of Idah, Dekina and Ankpa local government areas. Blood samples were collected from volunteered donors (men) aged 25-75 years. Questionnaire was used to collect the demographic data from the subjects for 
analysis. Sixty five questionnaires were given out; five were considered invalid due to errors in filling the form by the respondents. Ten (10) questionnaires were given to control subjects from people aged 25 - 34 years old. All the questionnaires were accepted and used as being valid for the analysis.

\section{Sample Preparation}

Blood samples were collected from the volunteered donors; men aged 25years and above through venipuncture, into EDTA coated tubes and plain tubes for the biochemical test. The samples were centrifuged at $4000 \mathrm{rpm}$ for 5 minutes using uniscope laboratory centrifuge model SM 112 to obtain the serum required for analysis.

\section{Determination of activities of serum Alkaline Phosphatase}

The method described by Englehardt (1970) was used to determine the activity of alkaline phosphatase. $1 \mathrm{ml}$ of reconstituted working reagent (diethanolamine buffer, $\mathrm{MgCl}_{2}$ and $\mathrm{p}$ nitrophenylphosphate) was added to $0.02 \mathrm{ml}$ of sample mixed and timer started simultaneously. The absorbance was read after 1, 2 and 3 minutes at $405 \mathrm{~nm}$.

\section{Calculation}

$\operatorname{ALP}$ activity $(\mathrm{U} / \mathrm{L})=2760 \times \Delta \mathrm{A} 405 \mathrm{~nm} / \mathrm{min}$

\section{Determination of the activities of serum Alanine Aminotransferase (ALT)}

According to Reitman and Frankel, (1957), $0.1 \mathrm{ml}$ of sample was added to $0.5 \mathrm{ml}$ of working reagent R1 (phosphate buffer, L-aspartate, a-oxoglutarate) after this, mixed and incubated at $3^{\circ} \mathrm{C}$ for 30 minutes with $0.5 \mathrm{ml}$ of working reagent 2 (R2) (2,4-dinitrophenylhydrazine). This was mixed and allowed to stand for 20 minutes at room temperature of between $20^{\circ} \mathrm{C}-25^{\circ} \mathrm{C}$. The reaction was terminated with the addition of $5 \mathrm{ml}$ of $\mathrm{NaOH}$ and the absorbance was read after 5 minutes at $546 \mathrm{~nm}$.

\section{Calculation}

AST activity $(\mathrm{U} / \mathrm{L})=$ Change in Absorbance $\mathrm{X}$ concentration

\section{Determination of the activities of serum Aspartate Aminotransferase (AST)}

The procedure described by (Reitman and Frankel, 1957) was used for the determination of Aspartate amino transferase activity. To $0.1 \mathrm{ml}$ of sample, $0.5 \mathrm{ml}$ of working reagent R1 (phosphate buffer, L-aspartate, a-oxoglutarate) was added, mixed and incubated at $37{ }^{\circ} \mathrm{C}$ for 30 minutes with $0.5 \mathrm{ml}$ of working reagent 2 (R2) (2,4-dinitrophenylhydrazine). This was mixed and allowed to stand for 20 minutes at room temperature of between $20^{\circ} \mathrm{C}-25^{\circ} \mathrm{C}$. The reaction was terminated with the addition of $5 \mathrm{ml}$ of $\mathrm{NaOH}$ and the absorbance was read after 5 minutes at $546 \mathrm{~nm}$.

\section{Calculation}

AST activity $(\mathrm{U} / \mathrm{L})=$ Change in Absorbance $\mathrm{X}$ concentration

\section{Determination of serum cholesterol}

The method of Friedewald et al. (1972) was used to determined serum total cholesterol concentration.

\section{Determination of High Density Lipoprotein:}

The method of Friedewald et al. (1972) was used to determined serum total cholesterol concentration. 


\section{Determination of Serum Triglyceride Concentration:}

The method of Jacobs and Van Denmark (1960) was employed in the determination of serum Triglyceride concentration.

\section{Determination of Low density lipoprotein}

Values for low density lipoprotein were calculated using Friedwald equation below, LDL Cholesterol=Total cholesterol- Triglycerides - HDL Cholesterol

\section{Statistical Analysis}

Data were initially sorted out manually and tabulated and then entered into the computer using bonferon comparison test of graph pad with statistical software and the mean value determined, and the differences were considered significant if $p<0.05$. Comparison of mean values in relation to age distribution was done using analysis of variance (ANOVA).

\section{RESULTS}

Variation of the serum alkaline phosphatase (ALP) with age

There were increased serum alkaline phosphatase in groups 3, 5 and 6 compared to the control group 1 while decreased in groups 2 and 4, though not significant. This could indicate a slight damage to the liver.

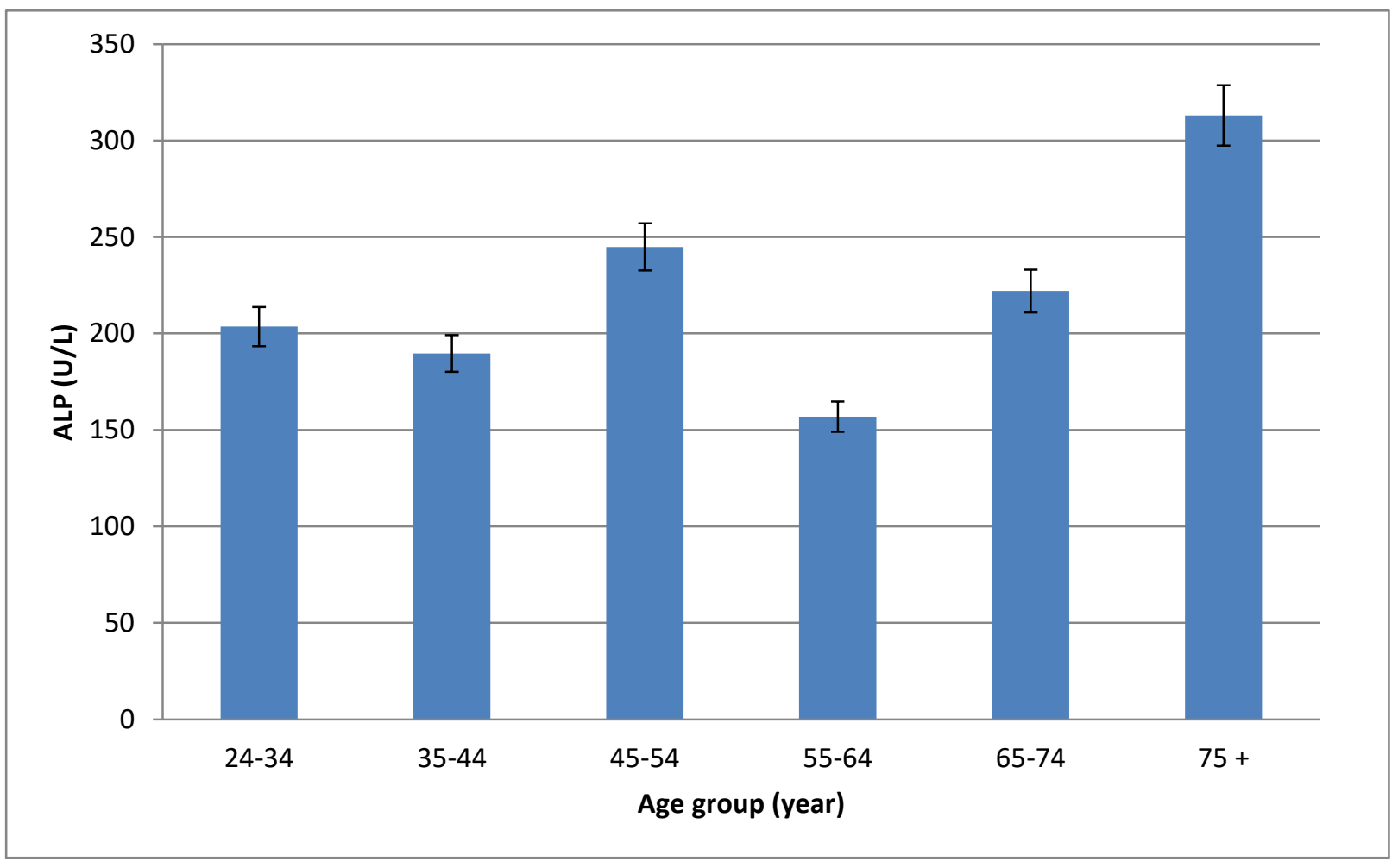

Fig. 1: Barchart showing Alkaline Phosphatase activity in aged men, $n=60$

Variation of the serum Alanine transaminase (ALT) with age

Figure 2 shows significant increase in serum ALT in all groups. Group 2 and 4 have the highest concentration compared to control group 1. 


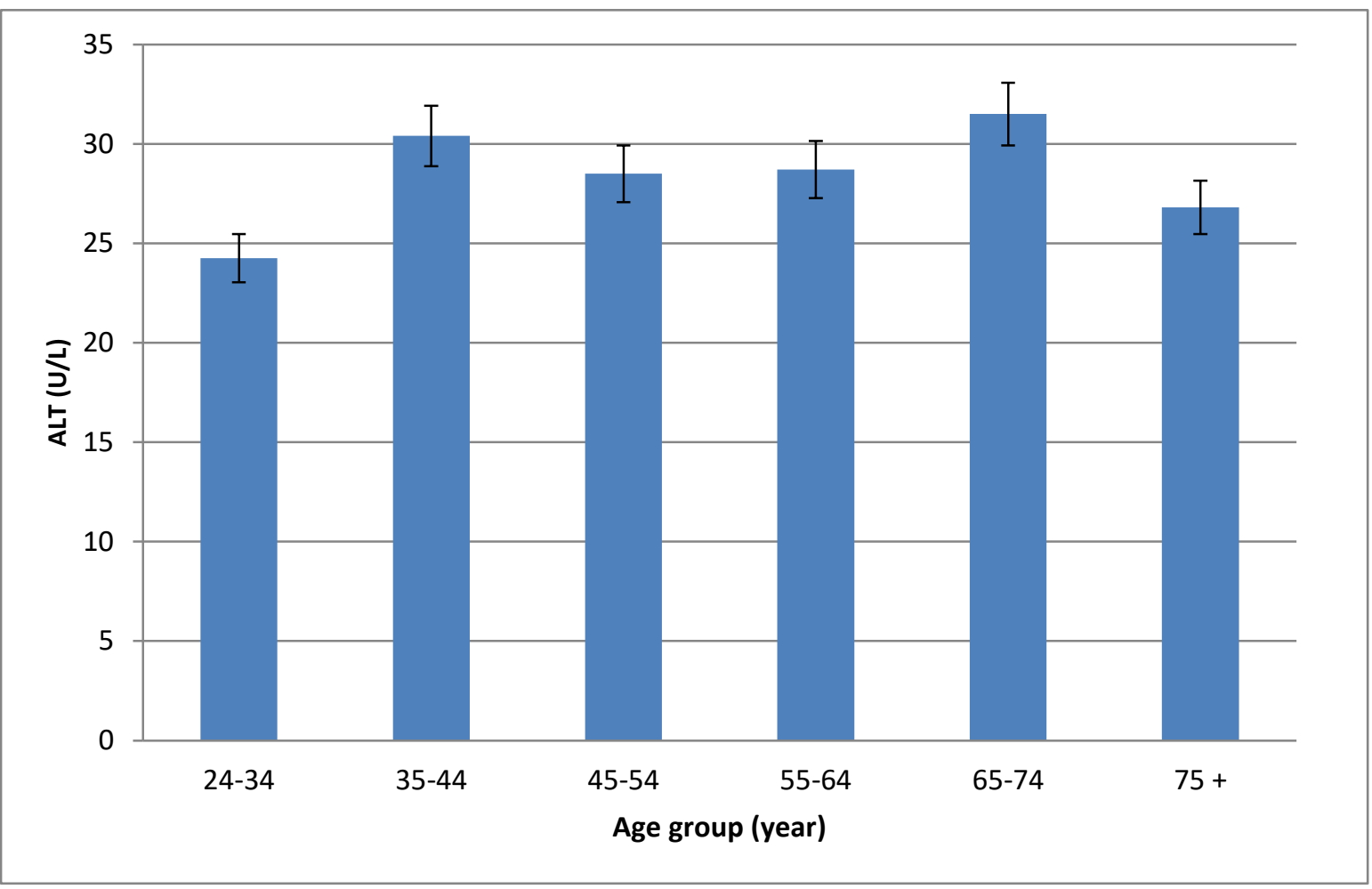

Fig. 2: Bar chart showing Alanine Aminotransferase activity in aged men, $n=60$

\section{Variation of the total cholesterol with age}

Figure 3 shows increases in the total cholesterol in all groups. Group 3 (45-54 year) have a significant increase $(\mathrm{p}<0.05)$.

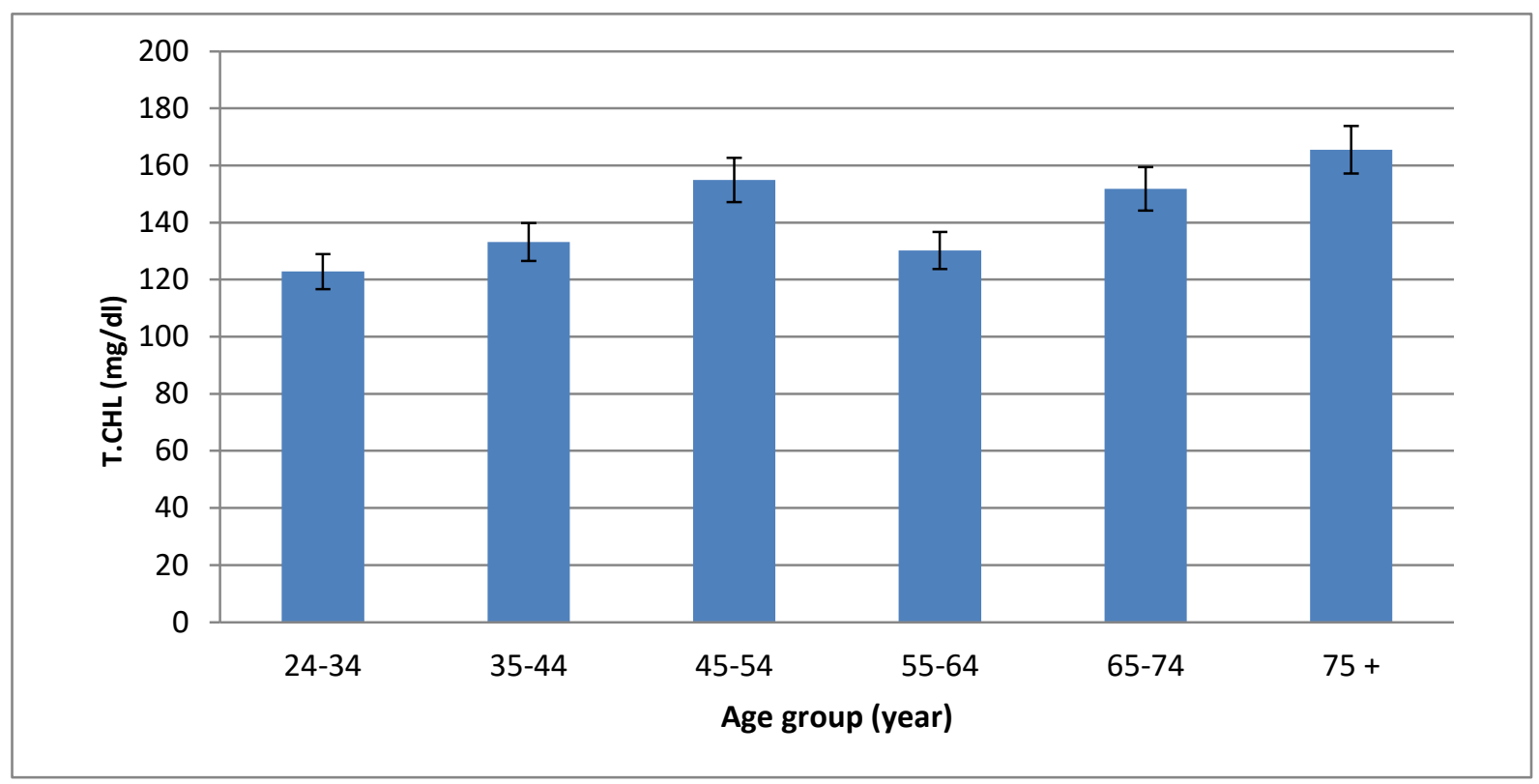

Fig. 3: Bar chart showing total cholesterol concentration in aged men, $n=60$ 


\section{Variation of the high density lipoprotein with age}

In fig.4, there is a steady significant increase $(p<0.05)$ in HDL in group 3 and 4 when compared to the control group 1 while a significant decrease also occurred in group $5(\mathrm{p}<$ 0.05).

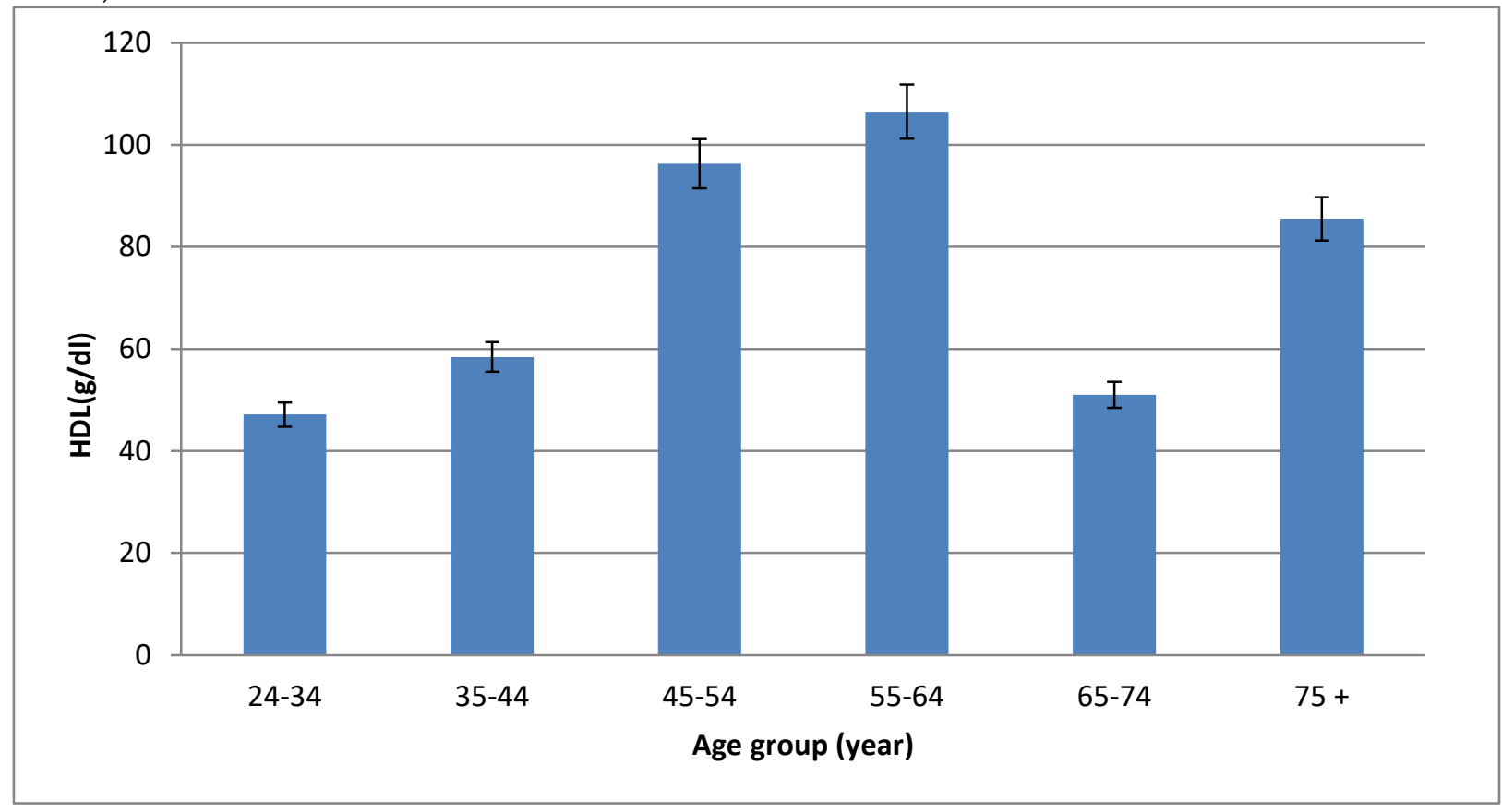

Fig. 4: Bar chart showing High Density Lipoprotein in aged men, $n=60$

\section{Variation of the low density lipoprotein with age (LDL)}

Figure 5 shows significant increase in LDL in group 3 and $5(\mathrm{p}<0.05)$ while group 2 and 4 shows decrease. These increases could be as a result of the social and nutritional lifestyle such as eating food rich in saturated fats, smoking, etc.

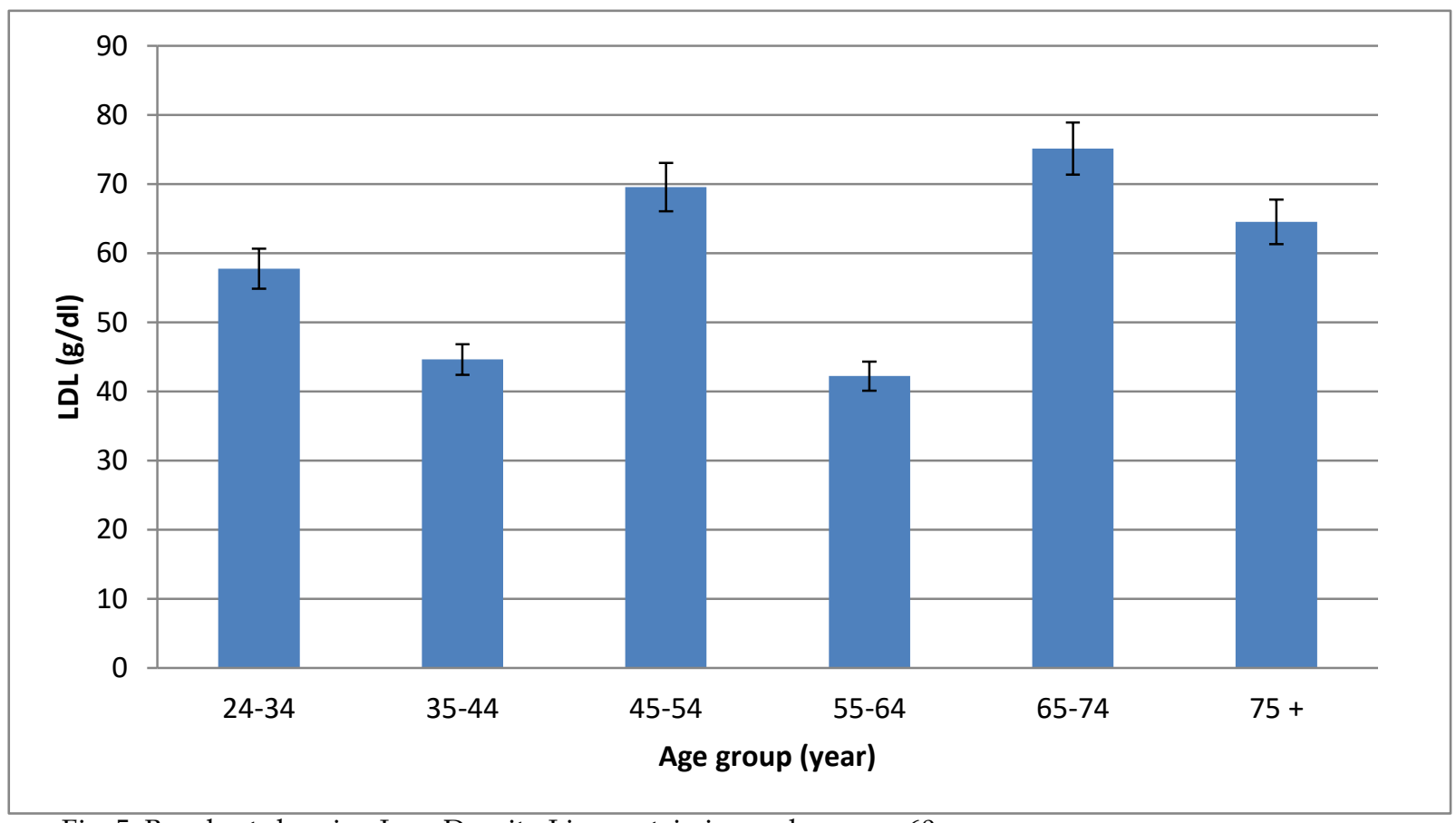

Fig. 5: Bar chart showing Low Density Lipoprotein in aged men, $n=60$ 


\section{Variation of the very low density lipoprotein with age}

Figure 6 shows a significant increase $(p<0.05)$ in VLDL in group 2 and 4 and decreases in group 5 and 6 showing that VLDL increases with age. The significant increase of VLDL in group 4 could be as a result of high saturated fatty food content in the diets.

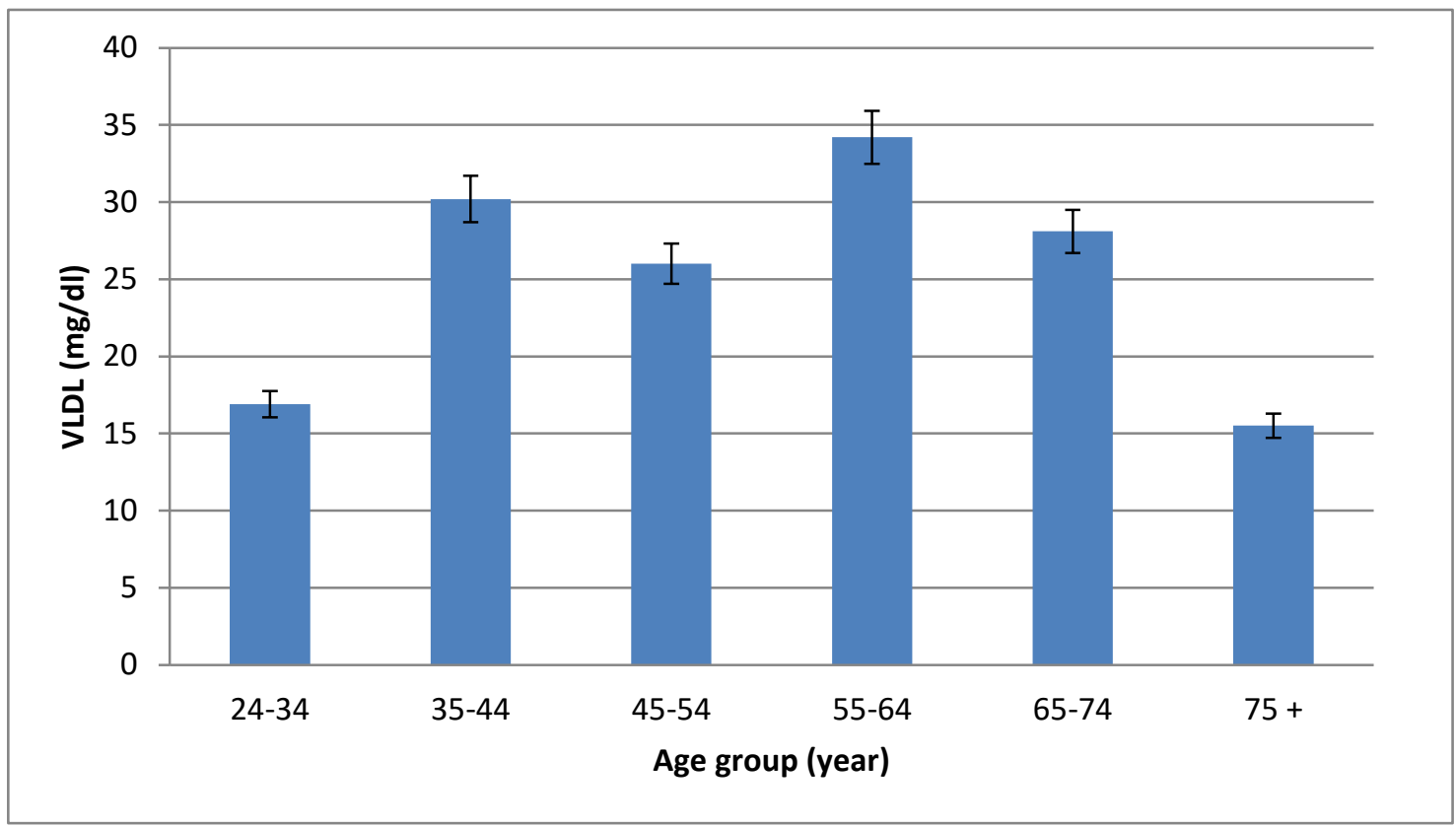

Fig.6: Bar chart showing Very Low Density Lipoprotein in aged men, n=60

\section{Variation of the triglyceride with age}

Figure 7 shows an increase in all groups except group (75- above) which shows a decrease in triglyceride when compared to the control group 1.This could be as a result of consumption of high fat calorie content.

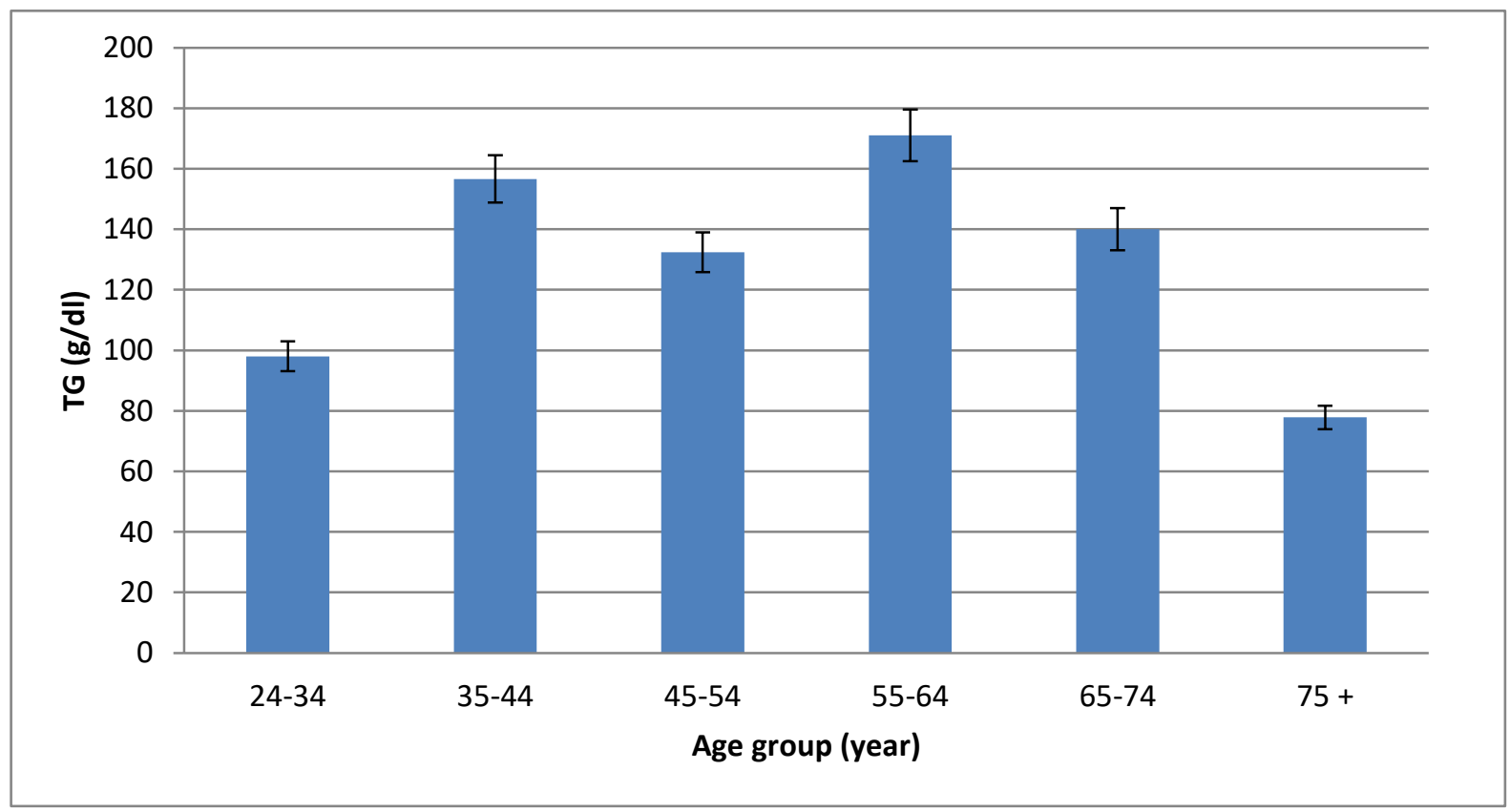

Fig. 7: Bar chart showing triglycerides concentration in aged men, $n=60$ 


\section{DISCUSSION}

Ageing affects different organs, tissues, and cell types in the same organism in different ways; that is, the extent of age-associated perturbations of structure and function is sitespecific. Aging in men enhances this negative influence of androgens on the lipid profile (Khaw \& Barrett-Connor, 1991; Zmuda et al., 1997;). The low levels of testosterone and high levels of free androgens index (defined as testosterone $(\mathrm{nmol} / \mathrm{L}) / \mathrm{SHBG}(\mathrm{nmol} / \mathrm{L}) \times 100)$ are associated with the atherogenic lipid profile in men (Andersen et al., 2000; Khaw \& BarrettConnor, 1991; Zmuda et al., 1997).

A significant increase in the high density lipoprotein occurred between the ages of $55-64$ and then decreased. HDL is also known as "good cholesterol". This probably indicated that the subjects in the age range were not at the risk of coronary heart disease. HDL helps to prevent atherosclerosis. Low density lipoprotein (bad cholesterol) helps to transport the contents of lipid molecules into the arterial walls, attract macrophages and thus drive atherosclerosis, while very low density lipoprotein showed no significant difference $(\mathrm{p}<0.05)$. Variation occurred in the triglyceride concentration with age as there was an increase between ages 55 - 64 while a decreased occurred as the age increased. High triglycerides could be as result of poorly controlled diabetes, obesity, drinking of alcohol and regularly eating more calories than one can burn.

\section{REFERENCES}

Andersen, A. G., Jensen, T. K., Carlsen, E., Jørgensen, N., Andersson, A. M., Krarup, T., Skakkabaek, N. E. (2000). High frequency of sub-optimal semen quality in an unselected population of young men. Human Reproduction, 15, 366-372

Bagatell, C. J., and Bremner, W. J. (1995). Androgen and progestagen effects on plasma lipids. Progress in Cardiovascular Diseases, 38, 255-271.

Friedewald, W.T., Levy, R.I., and Fredrickson, D.S. (1972). Estimation of the concentration of low density lipoprotein cholesterol in plasma, without the use of the preparative ultracentrifuge. Clinical Chemistry, 18(6),499-502.

Jacobs, N.., and Van Denmark, P. (1960). Enzymatic determination of serum triglyceride. J. Arch. Biochem. Biophy, 88, 250-255.

Khaw, K. T., and Barrett-Connor, E. (1991). Endogenous sex hormones, high density lipoprotein cholesterol, and other lipoprotein fractions in men. Arteriosclerosis and Thrombosis, 11, 489-494.

Reitman, S., and Frankel, S. (1957). A colorimetric method for the determination of serum glutamic oxaloacetic and glutamic pyruvic transaminases. American journal of clinical pathology, 28(1), 56-63.

Sampson, E. J., Whitner, V. S., Burtis, C. A., Mckneailey, S. S., Fast, D. M and Bayse, D. D. (1980). An inter laboratory evaluation of the IFCC method for aspartate aminotransferase with the use of purified enzyme materials. Clinical Chemistry, 26:1156-1164.

Sidhu, D and Naughler, C. (2012). "Fasting Time and Lipid levels in a Community- based Population: A Cross- Sectional Study/Fasting Time and Lipid Level". Archive of Internal Medicine.172 (22): 1-4

Zmuda, J. M., Cauley, J. A., Kriska, A., Glynn, N. W., Gutai, J. P., and Kuller, L. H. (1997). Longitudinal relation between endogenous testosterone and cardiovascular disease risk factors in middle-aged men. 13-year follow-up of former multiple risk factor intervention trial participants. American Journal of Epidemiology, 146, 609-617 